\title{
Change and Our Commitment to Continual Improvement
}

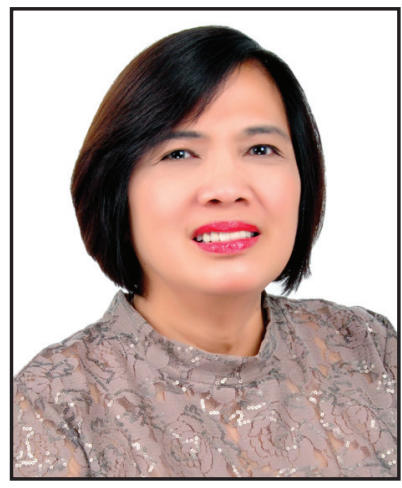

After six years of continuous, regular and timely publication of high quality endocrinology articles from the Southeast Asian region, we are pleased to announce that JAFES is now indexed in Scopus, one of the largest abstract and citation databases of peer-reviewed literature. Along with our efforts of adopting international standards, shifting to $100 \%$ open access, and utilization of technologies such as our Open Journal Systems-based website, CrossRef digital object identifiers for all published articles, and Similarity Check for plagiarism detection, our being indexed is aligned with our goal to make scientific output from the region global and accessible to a wider audience.

In addition to DOAJ, WPRIM, APAMED and Scopus, it is also our aim to be included in other indexing services, such as PubMed and Thomson Reuters.

Indexing in recognized and established databases increases journal visibility and searchability. The metrics embedded in these databases allow for the journal to analyze its performance and identify not only gaps but also opportunities for improvement. Inclusion is, also, a stamp of quality, as journals pass through rigorous screening, review and content selection.

As we continue our efforts of enhancing JAFES, we get to encounter not only technical but also editorial policy issues. The ICMJE Recommendations for the Conduct, Reporting, Editing, and Publication of Scholarly Work in Medical Journals serves as our general guideline for operations. We have registered in the World Association of Medical Editors (WAME) online forum, reading through questions and answers, posting our own questions and getting constructive feedback from peers from all over the globe. The Committee on Publication Ethics (COPE) flowcharts serve as a valuable resource when we are faced with suspected misconduct, such as duplicate publications, plagiarism, and authorship issues. We have also acknowledged the fact that even our own journal's editors publish in JAFES, but protecting the journal's objectivity by strictly inhibiting them from the deliberation, peer review process, and final decision.

We appreciate the importance of formally providing third party permissions for articles published in the JAFES when contacted several times by a copyright clearance center. Though all articles in the journal are open access to all, they are governed by a Creative Commons License BY-NC, that allows free use of the information provided there is proper attribution and strictly for non-commercial purposes only. Protecting the scientific output of our regional researchers from misuse, we shall keep all of you updated on this matter.

Finally, in the last Asia Pacific Association of Medical Editors' Conference in Thailand, we were introduced to the 2015 version of the GPP3 Guidelines, an update to the original Good Publication Practice (GPP) guidelines, and which we are adopting to strengthen the JAFES' stand on integrity and transparency for industry-sponsored medical publication. We are now realizing that the process of improvement of editorial policies and operations is a dynamic and continuous one, and our receptivity to change as we learn more from colleague editors from this region and the world, underscores our commitment to our readers..

Our official logo, the proverbial tree, continuously growing, spreading, tested by inclement weather and harsh seasons, getting only stronger with time, reminds us all that much have been accomplished, much remain to be done.

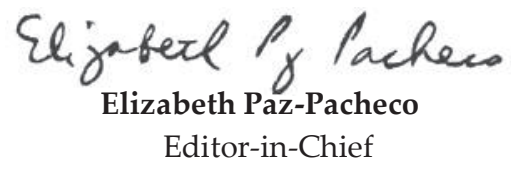

https://doi.org/10.15605/jafes.032.01.01

\section{References}

1. Battisti WP, Wager E, Baltzer L, et al. Good Publication Practice for Communicating Company-Sponsored Medical Research: GPP3. Ann Intern Med. 2015; 163(6): 461-4. https://doi.org/10.7326/M15-0288.

2. Davidoff F, DeAngelis C, Drazen J, et al. Sponsorship, authorship, and accountability. http://www.icmje.org/newsand-editorials/update_spon_sep2001.html. Accessed May 9, 2017. 